\title{
VALIDATION OF KPG INDEX "CLASSIFICATION METHOD TO PREDICT ORTHODONTIC TREATMENT DIFFICULTY LEVEL OF IMPACTED CANINES”
}

\author{
Ayesha Iftikhar, Tayyaba Jehanzeb \\ Rehman Collage of Dentistry, Peshawar Pakistan
}

\begin{abstract}
Objective: To determine the position of impacted canine in 3 dimensions and estimate the difficulty of treatment using 3D "KPG index", a new classification method.

Study Design: Cross sectional analytical study.

Place and Duration of Study: Orthodontic Department, Rehman College of Dentistry, Peshawar, from Aug to Oct 2020.

Methodology: 3D cone beam computed tomography (CBCT) scans of 43 subjects with 47 impacted canines were obtained. Using KPG index, 6 measurements were taken for each impacted tooth in three planes. The scores were later summed up. Based on the cumulative scores, each impaction was classified into the difficulty categories of Easy (0-7), Moderate (8-14), Difficult (15-19), and Extremely Difficult (20+). Comparison of Gender and position of impacted canine with the KPG treatment difficulty index was also performed.

Results: Impacted canines were found to be on the left and palatal side with a female predilection. Canines scored with KPG index were mostly in the moderate category. Highest percentage of the impacted canines were in Sector II, followed by sector III and IV. Comparing KPG treatment difficulty index of impacted maxillary canines found on the right and left sides $(p=0.087)$, buccal or palatal $(p=0.545)$, males and females $(p=0.279)$, in-statistically significant difference was found.

Conclusion: 3D imaging has allowed us to precisely locate the impacted canine in 3 sagittal, coronal and axial planes. Hence, KPG index dictated our anticipated difficulty of treatment.
\end{abstract}

Keywords: Canine impaction, KPG index, 3D cone beam computed tomography (CBCT).

This is an Open Access article distributed under the terms of the Creative Commons Attribution License (https://creativecommons.org/licenses/by-nc/4.0/), which permits unrestricted use, distribution, and reproduction in any medium, provided the original work is properly cited.

\section{INTRODUCTION}

Canines are considered as the cornerstones of the mouth and are important both for esthetics and function $^{1}$. Impaction of canines has been reported to be second most frequent after third molars ${ }^{1,2}$. (General prevalence of canine impaction is 1-3\%1,3. Recent study in Pakistan reported 5\% incidence of canine impaction in Orthodontic population ${ }^{1}$. About two third of the maxillary canines are reported to be on the palatal side ${ }^{4,5}$.

Etiology of canine impaction is multifactorial 3,6 , including genetics, systemic factors (endocrine disorders, febrile illness, irradiation) local obstruction, local pathology, missing/peg shaped laterals, lack of guidance from the laterals and complicated path of eruption etc $^{1,4,5}$.

Management of impacted canines is challenging for the orthodontist from both diagnostic and therapeutic point of view ${ }^{6}$. Traditionally, for the diagnosis and management orthodontist, mostly relied on clinical examination and radiographs ${ }^{2,4}$.

Conventionally, 2D radiographic assessment methods such as orthopantomogram (OPG), cephalometric radiography, and intraoral occlusal or periapical X-

Correspondence: Dr Ayesha Iftikhar, Department of Dentistry, Rehman College of Dentistry, Peshawar Pakistan

Received: 31 Dec 2020; revised received: 21 Feb 2021; accepted: 23 Feb 2021 rays are being used for the diagnosis and evaluation of impacted canines $1,7,8$. The diagnostic accuracy and validity of $2 \mathrm{D}$ methods can be underestimated. This can be related to limitations such as distortion of images, inability to assess sectional details in 3 dimensions, reduction of the original volume onto radiographic films due to patient positioning and superimpositions ${ }^{9}$.

Recently, cone beam computed tomography (CBCT) has been introduced with comparatively less radiation exposure and 3-Dimensional imaging capability for all the dental structures ${ }^{3}$. Today CBCT is preferred over 2D radiological methods due to its reliability and accuracy ${ }^{8}$. Nowadays, its clinical application has widened and is currently being used for maxillofacial, dental implantology and orthodontic purposes. The advantages of CBCT over medical CT are the isotropic voxel resolution, rapid scan time, limited radiation exposure, various field of view (FOV) and cost effectiveness ${ }^{3}$.

Various 2D classification systems have been formulated in past including Stewart, Ericson/Kurol, Lindauer and Chapokas 9 . These methods do not consider the buccolingual position of teeth and also need another set of radiographs for precise location of canine ${ }^{4}$. In 2009, KPG index was introduced. It is one of the first index that helps to understand the spatial relationship of the impacted tooth in $3 \mathrm{D}$ space ${ }^{10}$. This index was 
introduced to standardize diagnosis and predict treatment difficultyhelps to classify canine impactions in $X$, $Y \& Z$, planes and determine/estimate the difficulty of treatment ${ }^{10}$.

To best of our knowledge no study has been reported in Pakistan to determine the position and difficulty in management of impacted canine using 3D KPG index.

Therefore, the objective of this study was to use 3D KPG difficulty index to determine the position and to estimate the level of treatment difficulty of impacted canine. Comparisons of gender and position of the impacted canines were also performed with the KPG index. This will help the orthodontist to provide definite treatment plan to the patient both in terms of complexity and time.

\section{METHODOLOGY}

The cross sectional analytical study was initiated after the ethics approval from the Research Committee of the institute (ECF No. 2020-08-51). Pre-treatment records of the 43 subjects with impacted canines were collected by screening the orthodontic records at Rehman College of Dentistry, from 2017 to 2020 using consecutive sampling technique. Informed consent was taken from the patients about the use of records in research or for academic activity.
Sample size was calculated using $G$ power* (effect size $=0.55$, error $=0.05$, power $=0.95$ ).

Inclusion criteria was all unilateral and bilateral maxillary and mandibular canine impactions. Patients with craniofacial anomalies, cleft lip and palate, syndromes, traumatic injuries of jaws/teeth, previous surgeries were excluded from the study.

The sample was collected for all the patients who were referred by the orthodontist to have CBCT for diagnostic evaluation of exact position and location of impacted canines for both maxillary and mandibular regions. The sample included in 47 impacted canines from 32 patients. The images were taken with CBCT apparatus (CS 9000) at 60-90 kV, scanning time of 4-16 seconds, reconstruction time 2 minutes, slice thickness of $0.15 \mathrm{~mm}$, FOV $(50-37 \mathrm{~mm})$ and voxel (size $76 \times 76 \times$ $76 \mu \mathrm{m}$ ). Later overall image was assessed using CS 3600 3D imaging software. The impacted canine was appropriately manipulated in the $X, Y$, and $Z$ planes of space, and the software's measurement tool provided the millimetric data necessary to classify the position of canine using KPG Index. See fig-1 the index scored the canine impactions based on the distance from ideal position in three planes of space (sagittal, coronal and axial). Scoring was done for both the cusp tips and root tips. 6 scores were taken per tooth ranging from 0 -
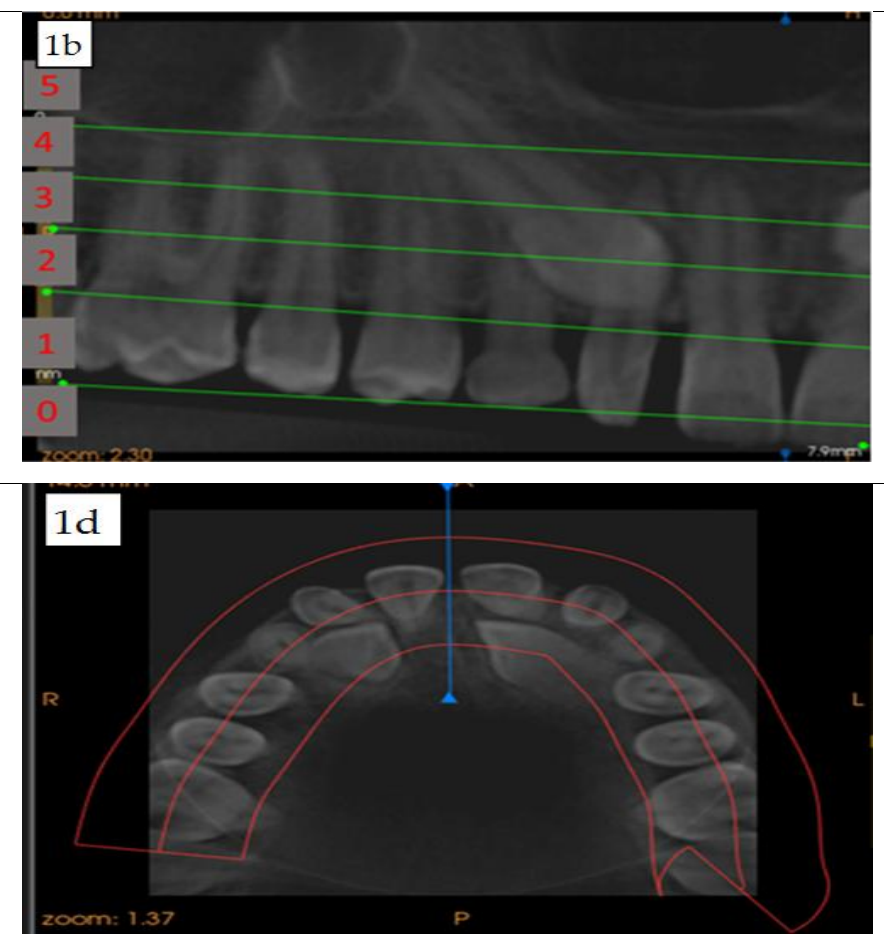
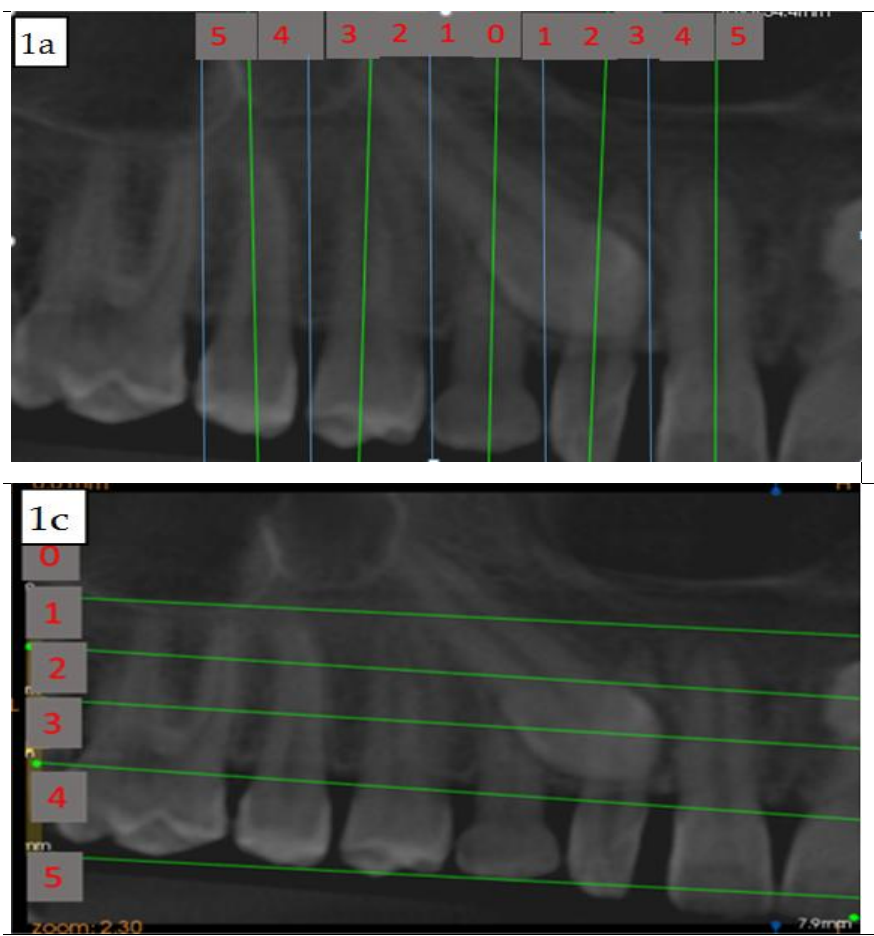

Figure-1: (A) Showing mesiodistal position $(X)$ for both cusp and root tips. In this example $C X=3, R X=2$, $(B)$ showing vertical position $(Y)$ cusp tip. In this example $C Y=3,(C)$ showing vertical $(Y)$ position of root TIP. In this example $R Y=0$, (D) showing occlusal reference arch and axial view $(Z)$ for both cusp and root TIP. Right $C Z=3, R Z=3$. Therefore, $K P G$ index value IS 11. $(3+2+3+0+3+3=11)$, considered As moderate category. 
5. These scores were later summed up. Based on the scores, each impaction was classified into the difficulty categories of Easy (0-7), Moderate (8-14), Difficult (1519), and Extremely Difficult $(20+)^{10,11}$.

Statistical analysis was done using IBM SPSS-20 (Chicago, III). Means and standard deviations were calculated for the descriptive data. The frequency and percentage was calculated for the qualitative data. Comparisons between gender, right and left side, buccal and palatal position of impacted canines with KPG difficulty index were performed using chi-square test. $p$-value $<0.05$ was considered significant.

Fig-1(a); showing Mesiodistal position ( $x$ ) for both cusp and root tips. In this example $C x=3, R x=2$, fig- $1(b)$ showing vertical position (y) cusp tip. In this example $\mathrm{Cy}=3$, fig-1(c); showing vertical (y) position of root tip. In this example $R y=0$, fig- $1 d$; Showing occlusal reference arch and axial view (z) for both cusp and root tip. Right $\mathrm{C} z=3, \mathrm{Rz}=3$. Therefore, $\mathrm{KPG}$ index value is 11 . $(3+2+3+0+3+3=11)$, considered as moderate category.

\section{RESULTS}

This study sample included (34; $72.3 \%$ female, 13 ; $27.7 \%$ male); mean age, $16.02 \pm 4.017$ years. Mean age of the sample was $16.02 \pm 4.017$ years. Most of the canines were on the palatal side $(68.1 \%)$ as compared to buccal side $(31.9 \%)$. Also, most of the impacted canines were on the left side $(51.1 \%)$ as compared to right side $(48.9 \%)$.

In this study CBCT scans of 47 impacted canines were scored for 3D KPG index and based on their position in $\mathrm{X}, \mathrm{Y}$ and $\mathrm{Z}$ planes they were scored and later were segregated from 1-4 difficulty categories. Mean value of the Cumulative score of the KPG index was 14 $0.66 \pm 3.205$ with a range of 12 . Most of impacted canines $(55.3 \%)$ were scored in moderate category, followed by difficult $(34 \%)$, extremely difficult $(8.5 \%)$, and easy category $(2.1 \%)$.

Gender comparisons with KPG index are given in table-I Most of the impacted canines were in moderate category in females (17 vs 9 males) followed by difficult category (14 vs 2 males). However, the difference was insignificant $(p=0.279)$.

Comparison between the KPG index treatment difficulty with the impacted canines found on the right and left side are shown in table-I. Most of the Impacted canines were on the right side and moderate category. However, the difference was insignificant $(p=0.545)$.

Comparison between KPG index treatment diffi-

Table-I: Chi-square test comparing gender and site (buccal/ palatal; right and left) with KPG treatment difficulty index. KPG index Categories \begin{tabular}{c|c} 
Right or Left & $\begin{array}{c}p \text { - } \\
\text { value }\end{array}$ \\
\hline
\end{tabular}

\begin{tabular}{|c|c|c|c|}
\hline & Right $(n=23)$ & Ieft $(n=$ & \multirow{5}{*}{0.545} \\
\hline 0-9 (Easy) & $1(4.3 \%)$ & - & \\
\hline 10-14 (Moderate) & $14(60.8 \%)$ & $12(50 \%)$ & \\
\hline 15-19 (Difficult) & $6(26.0 \%)$ & $10(41.6 \%)$ & \\
\hline $\begin{array}{l}\text { >20 (Extremely } \\
\text { Difficult }\end{array}$ & $2(8.6 \%)$ & $2(8.3 \%)$ & \\
\hline
\end{tabular}

\begin{tabular}{|c|c|c|c|}
\hline \multirow[t]{3}{*}{ Difficult } & $2(8.6 \%)$ & $2(8.3 \%)$ & \\
\hline & \multicolumn{2}{|c|}{ Buccal or Palatal } & \\
\hline & $\begin{array}{l}\text { Buccal } \\
(n=15)\end{array}$ & $\begin{array}{c}\text { Palatal } \\
(n=32)\end{array}$ & \\
\hline 0-9 (Easy) & $1(6.6 \%)$ & - & \multirow{4}{*}{0.087} \\
\hline 10-14 (Moderate) & $11(73.3 \%)$ & $15(46.8 \%)$ & \\
\hline 15-19 (Difficult) & $3(20 \%)$ & $13(40.6 \%)$ & \\
\hline \multirow[t]{3}{*}{$\begin{array}{l}>20 \text { (Extremely } \\
\text { Difficult }\end{array}$} & - & $4(12.5 \%)$ & \\
\hline & \multicolumn{2}{|c|}{ Gender } & \\
\hline & Female & Male & \\
\hline 0-9 (Easy) & $1(2.1 \%)$ & - & \multirow{4}{*}{0.279} \\
\hline 10-14 (Moderate) & $17(36.1 \%)$ & $9(19.1 \%)$ & \\
\hline 15-19 (Difficult) & $14(29.7 \%)$ & $2(4.2 \%)$ & \\
\hline $\begin{array}{l}\text { >20 (Extremely } \\
\text { Difficult }\end{array}$ & $2(4.2 \%)$ & $2(4.2 \%)$ & \\
\hline
\end{tabular}
$p \leq 0.05^{*}$

culty with the impacted canines found on buccal and palatal side (table-I). Mostly impacted canines were on the palatal side and moderate category. Although the difference was insignificant $(p=0.87)$.

When sectors (0-5) in three planes were assessed using KPG index. Mostly the impacted canines (crown and root tip) were in sector 3 , except root tip in x-axis was in sector 4 . None of the impacted canine was found in sector 0 except in root tip in y axis. In x-axis $23.8 \%$ canines crowns were in sector 3 and $34 \%$ roots were in sector 4 , In y-axis $29.18 \%$ were in sector 3 , In

Table-II: Canine impaction sectors in 3 planes of space (X, Y \& Z).

\begin{tabular}{c|c|c|c|c|c|c}
\hline \multirow{2}{*}{ Sectors } & $\begin{array}{c}\text { Canine X-axis } \\
\text { Crown }\end{array}$ & $\begin{array}{c}\text { Canine X-axis } \\
\text { Root }\end{array}$ & $\begin{array}{c}\text { Canine Y-axis } \\
\text { Crown }\end{array}$ & $\begin{array}{c}\text { Canine Y-axis } \\
\text { Root }\end{array}$ & $\begin{array}{c}\text { Canine Z-axis } \\
\text { Crown }\end{array}$ & $\begin{array}{c}\text { Canine Z-axis } \\
\text { Root }\end{array}$ \\
\hline 1 & $14(29.8 \%)$ & $1(2.1 \%)$ & $5(10.6 \%)$ & 0 & $1(2.1 \%)$ & $8(17.0 \%)$ \\
\hline 2 & $8(17.0 \%)$ & $11(23.4 \%)$ & $15(31.9 \%)$ & 0 & $6(12.8 \%)$ & $15(31.9 \%)$ \\
\hline 3 & $11(23.8 \%)$ & $14(29.8 \%)$ & $14(29.8 \%)$ & 0 & $18(38.8 \%)$ & $16(34.0 \%)$ \\
\hline 4 & $6(12.8 \%)$ & $16(34.0 \%)$ & $9(19.1 \%)$ & 0 & $15(31.9 \%)$ & $7(14.9 \%)$ \\
\hline 5 & $8(17.0 \%)$ & $5(10.6 \%)$ & $4(8.5 \%)$ & 0 & $7(14.9 \%)$ & $1(2.1 \%)$ \\
\hline
\end{tabular}


$\mathrm{z}$-axis crowns and roots were mostly in sector 3, 38.8\% and 34 respectively (table-II). Most of the impacted canines were found to be in sector $2(44.6 \%), 3$ (55.3\%) and 4 (39.9\%) (fig-2).

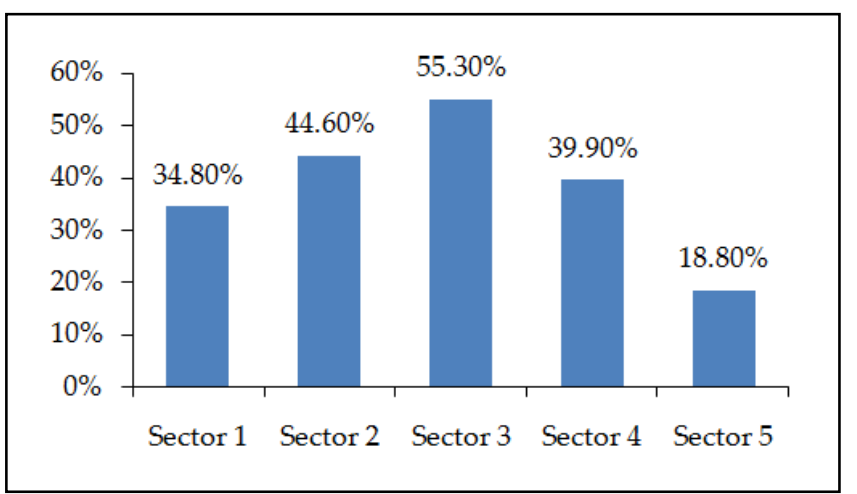

Figure-2: Sector distribution of impacted canines.

\section{DISCUSSION}

In dentistry, various classification systems are used to determine the difficulty or the status of the patient's dentition ${ }^{10,12}$. One of the first classification systems based on ideal position of molar relationship was proposed by Angle ${ }^{13,14}$. In orthodontics, to predict difficulty or duration of treatment various classification methods are being used based on 2D radiographs. These classification indices include Ericson and Kurol, Stewart's, and Chapokas analysis ${ }^{2,4,10}$. Recently, after the advent of CBCT based on 3D radiography15,16, KPG index is recently being used to assess the treatment difficulty and duration. According to Dalessandri et al, although KPG system is still a work in progress they proposed their first work in 2009 using 3D coordinates. This system has helped to categorize impacted canines in minimal amount of time to estimate the difficulty of management ${ }^{12}$. Therefore this study was aimed to determine the treatment difficulty of impacted canines using KPG index.

Most of the impacted canines in our study were on the palatal side with a female predilection. This is in line with the literature, across the globe and also Pakistan $13,4,16$. The higher frequency of canine impaction in females can be related to their small cranium that might lead to diminution of jaws and facial skeleton ${ }^{17}$. This trend can also be related to females being more concerned about their appearance, therefore are more willing to get their orthodontic treatment done ${ }^{17}$.

In our study most of the canines were in moderate category $(55.3 \%)$. This is in agreement with Daniel et al, who also reported that, $(53.57 \%)$ of impacted canines in their study to be in moderate category. In their study, 4 categories of difficulty were related to the ave- rage treatment duration. Moderate category took almost of 340.9 days or 11.36 month time and an extremely difficult category took 397 days or 13.23 months ${ }^{13}$. Similar, results of Beshlawy et al, also reported $33.3 \%$ of impacted canines in moderate category ${ }^{18}$.

The mean summative score of the sectors $(x, y, z)$ planes in our study was 14 . This score also confirms moderate category (7-14) of impacted canines. Theoretically, based on 0-5 score of the KPG index, total score should be 30. However, in $Y$ axis because of the origin of the canine high in the maxilla root tip is rated as 0 . To rate the canine root tip as 5, it has to cross the crown of the adjacent teeth ${ }^{11,19}$. Literature, suggests selection of the anatomical location is mostly at the discretion of the orthodontist and choosing a specific sector may influence the sum and so, the potential management and outcome. CBCT allows the accurate visualization of the canine's root tips in the axial planes. Beshlawy et al, suggested the use of a properly selected sagittal cut instead of axial cut is more accurate in determining the position of impacted canine ${ }^{18}$.

Most of the crown and root tips in three planes of space were in sector 3 , except the root tip in x-axis that was in sector 4 . Based on cumulative score, highest percentage of the impacted canines were in sector 3 followed by sector 2 and 4 . Studies of Lindauer's and Warford et al correspond to each other's and our findings. Impacted canines in their studies were mostly in Sector II, III \& IV ${ }^{11}$. Cuc et al reported palatal impacted canines in study were mostly found in in sector 4 and 5 as compared to the buccal canine impactions in sector 1.16 Literature suggests, determining the position of root tip of canine is very crucial as, proximity of the root to the adjacent structures can vary the real difficulty of impacted canine management $t^{6,20,21}$.

When KPG index treatment difficulty was compared with gender, although most of the impacted canines were found in females, the difference was insignificant. This is in accordance with the results of Beshlawy et al, who also reported insignificant difference. This shows that position of the impacted canine has minimal effect on patients, gender and the related management ${ }^{18}$. However, this is in contrast to the findings of Al Hammadi et al, who conducted a study on Saudi population on panoramic radiographs and reported difficulty index to be higher in males. The difference could be attributed to variation in selection of study population and methodology 22 .

Comparison of KPG treatment difficulty with right and left sides, revealed insignificant difference. Similarly, buccal and palatal position of impacted can- 
ine compared to KPG index, showed insignificant difference. The results are in accordance with previous studies, showing the side and position of the impacted tooth has no effect on the treatment difficulty of the impacted canines ${ }^{18}$.

It was a retrospective study. In future prospective clinical trials can be designed to compare the $2 \mathrm{D}$ and 3D methods to determine the difficulty level of the impacted canine. Also, prospective validation studies can be conducted to check the reliability of KPG index in our settings. Moreover, future research can be conducted to relate the difficulty of impacted canine with the type of management and approximate treatment duration.

\section{CONCLUSION}

3D imaging has allowed us to precisely locate the impacted canine in sagittal, coronal and axial plane the new 3D KPG index classification system incorporates 3-dimensional information in CBCT imaging. KPG index predicts difficulty of orthodontic treatment. Position, site and gender had no effect on treatment difficulty index.

\section{CONFLICT OF INTEREST}

This study has no conflict of interest to be declared by any author.

\section{REFERENCES}

1. Qadeer M, Khan H, Najam E, Anwar A, Khan T. Prevalence and patterns of mandibular impacted canines. a cbct based retrospective study. Pak Oral Dent J 2019; 38(2): 178-81.

2. Kim SH, Son WS, Yamaguchi T, Maki K, Kim SS, Park SB, et al. Assessment of the root apex position of impacted maxillary canines on panoramic films. Am J Orthod Dentofac Orthop 2017; 152(4): 489-93.

3. Servais JA, Gaalaas L, Lunos S, Beiraghi S, Larson BE, LeonSalazar V. Alternative cone-beam computed tomography method for the analysis of bone density around impacted maxillary canines. Am J Orthod Dentofac Orthop 2018; 154(3): 442-49.

4. Hamada Y, Timothius CJC, Shin D, John V. Canine impaction-A review of the prevalence, etiology, diagnosis and treatment. Semin Orthod 2019; 25(2): 117-23.

5. Caprioglio A, Comaglio I, Siani L, Fastuca R. Effects of impaction severity of treated palatally displaced canines on periodontal outcomes: a retrospective study. Prog Orthod 2019; 20(1): 5-8.

6. Dekel E, Nucci L, Weill T, Flores-Mir C, Becker A, Perillo L, et al. Impaction of maxillary canines and its effect on the position of adjacent teeth and canine development: A cone-beam computed tomography study. Am J Orthod Dentofacial Orthop 2020; S08895406(20): 30719-28.
7. Grisar K, Piccart F, Al-Rimawi AS, Basso I, Politis C, Jacobs R. Three-dimensional position of impacted maxillary canines: Prevalence, associated pathology and introduction to a new classification system. Clin Exp Dent Res 2019; 5(1): 19-25.

8. Tsolakis AI, Kalavritinos M, Bitsanis E, Sanoudos M, Benetou V, Alexiou K, et al. Reliability of different radiographic methods for the localization of displaced maxillary canines. Am J Orthod Dentofac Orthop 2018; 153(2): 308-14.

9. Björksved M, Magnuson A, Bazargani SM, Lindsten R, Bazargani F. Are panoramic radiographs good enough to render correct angle and sector position in palatally displaced canines. Am J Orthod Dentofac Orthop 2019; 155(3): 380-87.

10. Dalessandri D, Migliorati M, Visconti L, Contardo L, Kau CH, Martin C. KPG index versus OPG measurements: A comparison between $3 \mathrm{D}$ and $2 \mathrm{D}$ methods in predicting treatment duration and difficulty level for patients with impacted maxillary canines. Biomed Res Int 2014; 2014(1): 537620-25.

11. Chung HK, Pan P, Gallerano RL, English JD. A novel 3D classification system for canine impactions-the KPG index. Int J Med Robot Comput Assist Surg 2009; 5(3): 291-96.

12. Dalessandri D, Migliorati M, Rubiano R, Visconti L, Contardo L, Di Lenarda R, et al. Reliability of a novel CBCT-based 3D classification system for maxillary canine impactions in orthodontics: the KPG index. Sci World J 2013; 2013(1): 921234-38.

13. Daniel E. Martín S. The KPG index-a novel 3D classification system for maxillary canine impactions. Tex Dent J 2012; 129(3): 265-74.

14. Kau CH, Lee JJ, Souccar NM. The validation of a novel index assessing canine impactions. Eur J Dent 2013; 7(4): 399-404.

15. Tadinada A, Schneider S, Yadav S. Role of cone beam computed tomography in contemporary orthodontics. Semin Orthod 2018; 24(4): 407-15.

16. Ngo CTT, Fishman LS, Rossouw PE, Wang H, Said O. Correlation between panoramic radiography and cone-beam computed tomography in assessing maxillary impacted canines. Angle Orthod 2018; 88(4): 384-39.

17. Kifayatullah J, Bangash T, Ayub A, Khan D. Prevalence and Patterns of Impacted Maxillary Canine.Pak Oral Dent J 2015; 35(1): 57-61.

18. El Beshlawy D. Radiographic assessment of impacted maxillary canine position using CBCT: A comparative study of 2 methods. Egypt Dent J 2019; 65(4): 3393-402.

19. Stewart JA, Heo G, Glover KE, Williamson PC, Lam EWN, Major PW. Factors that relate to treatment duration for patients with palatally impacted maxillary canines. Am J Orthod Dentofac Orthop 2001; 119(3): 216-25.

20. Kau CH, Lee JJ, Souccar NM. The validation of a novel index assessing canine impactions. Eur J Dent 2013; 7(4): 399-404.

21. Eslami E, Barkhordar H, Abramovitch K, Kim J, Masoud MI. Cone-beam computed tomography vs conventional radiography in visualization of maxillary impacted-canine localization: A systematic review of comparative studies. Am J Orthod Dentofac Orthop 2017; 151(2): 248-58.

22. Alhammadi MS, Asiri HA, Almashraqi AA. Incidence, severity and orthodontic treatment difficulty index of impacted canines in Saudi population. J Clin Exp Dent 2018; 10(4): e327-34. 